\title{
Oral fluid antibody detection in the diagnosis of Helicobacter pylori infection
}

\author{
B. MARSHALL, A. J. HOWAT* and P. A. WRIGHT \\ Public Health Laboratory and *Department of Histopathology, Royal Preston Hospital, Sharoe Green Lane, \\ Preston PR2 9HG
}

\begin{abstract}
The aim of this study was to evaluate an enzyme-linked immunosorbent assay (ELISA) for the detection of anti-Helicobacter pylori specific IgG antibodies in specimens of oral fluid. Antral biopsy specimens, serum and oral fluid samples were collected from 81 patients attending for upper gastrointestinal endoscopy. The presence or absence of current $\boldsymbol{H}$. pylori infection was determined by culture, histology and urease detection. Anti- $H$. pylori specific IgG was detected in serum by an established in-house ELISA and in oral fluid by an ELISA developed for this study. In all, $34(42 \%)$ of 81 patients were positive for $\boldsymbol{H}$. pylori by one or more of the 'gold standard' tests (culture, histology and urease detection). The oral fluid ELISA had a sensitivity of $94 \%$ and specificity of $85 \%$ with regard to current $\boldsymbol{H}$. pylori infection. The serum ELISA had a sensitivity and specificity of $91 \%$. There was an overall agreement of $88 \%$ between serum and oral fluid antibody detection. The detection of anti- $H$. pylori specific IgG in oral fluid by ELISA is comparable in sensitivity and specificity with serum-based methods. Oral fluid-based ELISA could provide a reliable, non-invasive method for the diagnosis of $\boldsymbol{H}$. pylori infection, and may be of particular benefit for population surveys.
\end{abstract}

\section{Introduction}

Helicobacter pylori is now accepted as the major cause of chronic active gastritis, duodenal and gastric ulceration [1], and is associated with the development of gastric carcinoma [2]. H. pylori infection is also strongly associated with mucosal-associated lymphoid tumours (MALTs) and it has been reported that eradication of $H$. pylori may lead to improvement in tumour histology [3].

Oral fluid is a complex mixture of saliva secreted by parotid and other salivary glands, gingival crevicular fluid from the gingival crevice and secretions from the mucous membranes. This mixture is sometimes called mixed saliva. The term 'oral fluid' is used in this paper to describe this mixed saliva. Gingival crevicular fluid is a transudate present in the gingival crevice in the mouth. It more closely resembles serum than salivary gland secretions. IgG, present in oral fluid, is derived from this transudate and is found at a concentration substantially lower than the serum concentration; serum

Received 7 Jan. 1999; accepted 9 April 1999.

Corresponding author: Dr B. Marshall (e-mail: micro@) presphls.demon.co.uk). levels are 500-1500 times higher than oral fluid levels [4]. The oral fluid levels of IgG are still of sufficient concentration to be detectable by immunoassays. Immunoassays for the detection of antibodies to HIV [5-8], hepatitis A [8], hepatitis B virus core [8], rubella [8] and more recently $H$. pylori $[9-12]$ in oral fluid have been described. Oral fluid has been used in epidemiological studies of HIV infection in developing countries [7] and potentially has a role in seroepidemiological studies of other infectious agents.

The present study evaluated an in-house enzyme-linked immunosorbent assay (ELISA) for the detection of anti- $H$. pylori specific IgG in oral fluid, comparing this with culture, histology and urease detection, and with an established in-house serum-based assay.

\section{Materials and methods}

Patients attending for upper gastrointestinal tract endoscopy were asked to take part in the study and informed consent was obtained from those patients willing to participate. A sample of oral fluid and a blood sample were collected before endoscopy and three biopsy specimens were collected from the gastric antrum during endoscopy. 
The following patient groups were excluded from the study: those aged $<18$ years; pregnant patients; patients with bleeding diatheses and those on anticoagulants; patients who had taken antibiotics, or proton pump inhibitors or bismuth preparations in the previous 4 weeks. Ethical committee approval was granted for this study.

The oral fluid specimens were collected with the Omni-SAL device (Saliva Diagnostic Systems, Sovereign Court, London E1 9HW) and were processed according to the manufacturer's instructions. This device consists of an absorbant pad on the end of a plastic handle. The pad is placed under the tongue and collects a mixed saliva sample. The oral fluid eluate was frozen and stored at $-20^{\circ} \mathrm{C}$ until required. The blood specimens collected were allowed to clot and the sera were separated. The sera were frozen and stored at $-20^{\circ} \mathrm{C}$ until required. Antral biopsy specimens were collected for culture for $H$. pylori, histology and rapid urease testing by the CLO test (Delta West Pty, Bentley, Australia). Culture of the biopsy specimens was set up in the endoscopy suite on chocolate agar and on selective agar - Campylobacter Blood Free Base (LabM, Bury, Lancs) with horse blood $10 \%$, cefsulodin $5 \mathrm{mg} / \mathrm{L}$, amphotericin $10 \mathrm{mg} / \mathrm{L}$ and vancomycin $10 \mathrm{mg} / \mathrm{L}$. The plates were incubated micro-aerobically for 3 or 4 days and examined for colonies suggestive of $H$. pylori, which were further identified by Gram's stain, catalase, oxidase and urease activity. Culture plates negative for $H$. pylori after the initial incubation period of 3 or 4 days were re-incubated for a further 3 days before being considered negative. Histological diagnosis consisted of the detection of $H$. pylori-like organisms in haematoxylin and eosin-stained, silver-stained (Warthin-Faulkner method) and immunoperoxidasestained sections with a locally developed polyclonal anti- $H$. pylori antibody with DAB as the chromagen. CLO tests were incubated for up to $24 \mathrm{~h}$. Serological diagnosis was by ELISA following an established inhouse method $[13,14]$. The in-house oral fluid-based ELISA used the following method. A microtitration plate (Nunc 2-62162) was coated with antigen overnight at $4^{\circ} \mathrm{C}$. On the following day the plate was washed with phosphate-buffered saline containing Tween and $100 \mu \mathrm{l}$ of oral fluid were added to each well. The plate was incubated for $1 \mathrm{~h}$ at room temperature. The plate was then washed and $100 \mu \mathrm{l}$ of a 1 in 2000 dilution of horseradish peroxidase-labelled rabbit antihuman IgG (Dako Ltd, Ely, Cambs) in bovine serum albumin $1 \%$ was added to each well. The plate was incubated for $1 \mathrm{~h}$ then washed. Substrate solution $(100 \mu \mathrm{l}: 0.1 \mathrm{~g} o$-phenylene diamine in $100 \mathrm{ml}$ of substrate buffer activated with $80 \mu \mathrm{l}$ of $\mathrm{H}_{2} \mathrm{O}_{2} 30 \%$ ) was added to each well and incubated at room temperature in the dark for $10 \mathrm{~min}$ before the addition of $25 \mu \mathrm{l}$ of $2 \mathrm{M}$ sulphuric acid to stop the reaction. Optical density (OD) readings were measured at a wavelength of $490 \mathrm{~nm}$.
The antigen used in the oral fluid ELISA consisted of the supernate of a sonicate of $H$. pylori cells. Five strains of H. pylori were used, including NCTC 11916 and four locally isolated strains. The supernate from these five strains was pooled and used as the antigen. This antigen possessed urease activity. The antigen was titrated to determine the optimal dilution for use in the assay.

The sensitivity, specificity and positive and negative predictive values of the oral fluid ELISA and the serum ELISA were calculated by using the detection of $H$. pylori in antral biopsy specimens by culture or histology or urease production, or any combination of these, as the 'gold standard'.

\section{Results}

A total of 90 patients consented to take part in the study. Nine of these were excluded due to contravention of trial criteria (six patients had received proton pump inhibitors in the preceding 4 weeks), or inadequate samples (three patients), leaving 81 patients who provided adequate serum, oral fluid and biopsy specimens. These were 38 men and 43 women, with a mean age of 52.8 years (range $21-77$ ); 59 patients were $>45$ years old. Thirty-four $(42 \%)$ of the 81 patients were positive for $H$. pylori by one or more of the 'gold standard' tests (culture, histology and urease detection). The remaining 47 patients were negative for H. pylori by all three tests. The pattern of results for culture, histology and urease detection is given in Table 1. In developing the oral fluid ELISA, the sensitivity and specificity of the assay were calculated for various possible OD cut-off values, some of which are shown in Table 2. An OD cut-off value of 0.3 was used for the oral fluid ELISA, as this gave the best compromise between sensitivity and specificity. With this cut-off value the oral fluid ELISA had a sensitivity of $94 \%$ and a specificity of $85 \%$ with regard to current infection. The sensitivity, specificity, positive predictive value, negative predictive value and accuracy for the oral fluid ELISA with an OD cut-off value of 0.3 , and for the serum ELISA are shown in Table 3. There was $88 \%$ agreement between the results for serum and oral fluid antibody detection. There were insufficient patients to allow age-specific sensitivity and specificity rates to be calculated.

Table 1. Pattern of results for culture, histology and urease detection

\begin{tabular}{lccc}
\hline Culture & Histology & Urease detection & Number of patients \\
\hline+ & + & + & 26 \\
+ & + & - & 1 \\
- & + & + & 4 \\
+ & - & + & 1 \\
+ & - & - & 2 \\
- & - & - & 47 \\
\hline
\end{tabular}


Table 2. Sensitivity and specificity of the oral fluid ELISA at different cut-off values

\begin{tabular}{ccc}
\hline OD cut-off value & Sensitivity (\%) & Specificity (\%) \\
\hline 0.1 & 100 & 43 \\
0.2 & 100 & 70 \\
0.3 & 94 & 85 \\
0.4 & 91 & 85 \\
0.5 & 82 & 87 \\
0.6 & 76 & 91 \\
0.7 & 74 & 94 \\
0.8 & 71 & 96 \\
0.9 & 62 & 96 \\
1.0 & 62 & 96 \\
\hline
\end{tabular}

\section{Discussion}

An ELISA for the detection of $H$. pylori-specific IgG in oral fluid was evaluated by comparison with the 'gold standard' of culture, histology and urease detection. However, this 'gold standard' is imperfect. This study group yielded eight patients with discrepant results for culture, histology or urease detection, or a combination of the tests. Discrepant results for culture, histology and urease detection can occur for a number of reasons $[15,16]$. The oral fluid assay performed reasonably well. As with all serological tests there is a compromise between sensitivity and specificity, and an OD cut-off value of 0.3 gave the best compromise. The sensitivity and specificity obtained for the oral fluidbased ELISA are comparable with those of commercially available serum-based ELISA kits, which gave results for sensitivity and specificity in the ranges 70 $92 \%$ and $51-82 \%$, respectively, in the recent Medical Devices Agency evaluation report [17]. The sensitivity and specificity of the assay are similar to those in a recently published saliva-based ELISA used in children [10], which had a sensitivity of $93 \%$ and specificity of $82 \%$. The sensitivity is superior to other previously published saliva ELISA results which adapted a commercially available serum-based ELISA kit for use with saliva (sensitivity of $85 \%$ ) [11], or which used a commercially available oral fluid ELISA kit (sensitivity of $81 \%$ in one study, $88 \%$ in another) $[9,12]$. Sensitivity is comparable to culture, histology and urease detection.

Antibodies against $H$. pylori remain detectable for many months after $H$. pylori has been eradicated [18]. Those individuals with detectable anti- $H$. pylori $\mathrm{IgG}$ but no evidence of current $H$. pylori infection may represent patients in this post-treatment period. $H$. pylori infection in the stomach may be patchy due to intestinal metaplasia, or re-growth after failed eradication therapy. Biopsy specimens sample only a very small part of the stomach. In contrast, antibody detection methods effectively sample the whole stomach. False positive results obtained by antibody detection methods may in fact be false negatives by culture, histology and urease detection when there is only patchy infection. It should also be noted that all biopsy specimens in the present study were from the gastric antrum. The use of proton pump inhibitors can result in a decrease in the number of $H$. pylori organisms colonising the gastric antrum, with an increase in the numbers colonising the fundus [19]. Patients who had received proton pump inhibitors in the preceding 4 weeks were excluded from the present study, but information pertaining to their use prior to this was unavailable. Their prior use may explain some of the apparent false positive results in the serum and oral fluid antibody detection assays.

It should be remembered that the positive and negative predictive value of any test is dependent on the prevalence of the organism within a particular population. The positive and negative predictive values quoted for the oral fluid ELISA are based on this study group consisting of symptomatic patients referred for endoscopy, of whom $42 \%$ were infected with $H$. pylori. In a population with a lower prevalence of $H$. pylori infection the positive predictive value of the assay would be lower and the negative predictive value higher.

This study supports previous work [9-12] suggesting that antibody detection in oral fluid is a useful diagnostic test for $H$. pylori infection. This fact, combined with the ease of collection of oral fluid samples, produces another potential tool for seroepidemiological studies of $H$. pylori infection.

This work was supported by a grant from the Preston and Chorley Hospitals Research Fund.

\section{References}

1. Blaser MJ, Perez-Perez GI, Lindenbaum $\mathrm{J}$ et al. Association of infection due to Helicobacter pylori with specific upper gastrointestinal pathology. Rev Infect Dis 1991; 13 Suppl 8: S704-708.

2. The Eurogast Study Group. An international association between Helicobacter pylori infection and gastric cancer.

Table 3. Performance characteristics of the oral fluid and serum assays

\begin{tabular}{|c|c|c|c|c|c|c|c|c|}
\hline \multirow[b]{2}{*}{ Assay } & \multirow[b]{2}{*}{ Result } & \multicolumn{2}{|c|}{ Gold standard } & \multirow{2}{*}{$\begin{array}{c}\text { Sensitivity } \\
(\%)\end{array}$} & \multirow{2}{*}{$\begin{array}{c}\text { Specificity } \\
(\%)\end{array}$} & \multirow{2}{*}{$\begin{array}{l}\text { PPV } \\
(\%)\end{array}$} & \multirow{2}{*}{$\begin{array}{c}\text { NPV } \\
(\%)\end{array}$} & \multirow{2}{*}{$\begin{array}{c}\text { Accuracy } \\
(\%)\end{array}$} \\
\hline & & + & - & & & & & \\
\hline \multirow[t]{2}{*}{ Oral fluid ELISA } & + & 32 & 7 & 94 & 85 & 82 & 95 & 89 \\
\hline & - & 2 & 40 & & & & & \\
\hline \multirow[t]{2}{*}{ Serum ELISA } & + & 31 & 4 & 91 & 91 & 89 & 93 & 91 \\
\hline & - & 3 & 43 & & & & & \\
\hline
\end{tabular}

Oral fluid results based on an OD cut-off value of 0.3 ; PPV, positive predictive value; NPV, negative predictive value. 
Lancet 1993; 341: 1359-1362.

3. Bayerdörffer E, Neubauer A, Rudolph B et al. Regression of primary gastric lymphoma of mucosa-associated lymphoid tissue type after cure of Helicobacter pylori infection. Lancet 1995; 345: 1591-1594.

4. Shillitoe EJ, Lehner T. Immunoglobulins and complement in crevicular fluid, serum and saliva in man. Arch Oral Biol 1972; 17: 241-247.

5. Connell JC, Parry JV, Mortimer PP, Duncan J. Novel assay for the detection of immunoglobulin $\mathrm{G}$ antihuman immunodeficiency virus in untreated saliva and urine. J Med Virol 1993; 41: $159-164$.

6. Emmons WW, Paparello SF, Decker CF, Sheffield JM, LoweBey FH. A modified ELISA and western blot accurately determine anti-human immunodeficiency virus type 1 antibodies in oral fluids obtained with a special collecting device. $J$ Infect Dis 1995; 171: 1406-1410.

7. Frerichs RR, Htoon MT, Eskes N, Lwin S. Comparison of saliva and serum for HIV surveillance in developing countries. Lancet 1992; 340: 1496-1499.

8. Parry JV, Perry KR, Mortimer PP. Sensitive assays for viral antibodies in saliva: an alternative to tests on serum. Lancet 1987; 2: 72-75.

9. Christie JML, McNulty CAM, Shepherd NA, Valori RM. Is saliva serology useful for the diagnosis of Helicobacter pylori? Gut 1996; 39: 27-30.

10. Luzza F, Oderda G, Maletta $M$ et al. Salivary immunoglobulin $\mathrm{G}$ assay to diagnose Helicobacter pylori infection in children. $J$ Clin Microbiol 1997; 35: 3358-3360.

11. Patel P, Mendall MA, Khulusi S et al. Salivary antibodies to Helicobacter pylori: screening dyspeptic patients before endo- scopy. Lancet 1994; 344: 511-512.

12. Simor AE, Lin E, Saibil F et al. Evaluation of enzyme immunoassay for detection of salivary antibody to Helicobacter pylori. J Clin Microbiol 1996; 34: 550-553.

13. Bolton FJ, Hutchinson DN. Evaluation of three Campylobacter pylori antigen preparations for screening sera from patients undergoing endoscopy. $J$ Clin Pathol 1989; 42: 723-726.

14. Bolton FJ, Hutchinson DN, Hinchliffe PM, Holt AV. Distribution in various clinical groups of antibody to $C$. pylori detected by enzyme-linked immunosorbent assay, complement fixation and microagglutination tests. Serodiagn Immunother Infect Dis 1989; 3: $41-50$.

15. Goodwin CS, Blincow ED, Warren JR, Waters TE, Sanderson $\mathrm{CR}$, Easton L. Evaluation of cultural techniques for isolating Campylobacter pyloridis from endoscopic biopsies of gastric mucosa. J Clin Pathol 1985; 38: 1127-1131.

16. Marshall BJ, McGechie DB, Rogers PA, Glancy RJ. Pyloric campylobacter infection and gastroduodenal disease. Med $J$ Aust 1985; 142: 439-444.

17. Medical Devices Agency. Sixteen EIAs for the detection of antibodies to Helicobacter pylori. Medical Devices Agency Evaluation report MDA/97/55. London, Medical Devices Agency.

18. Kosunen TU, Seppälä K, Sarna S, Sipponen P. Diagnostic value of decreasing $\operatorname{IgG}, \operatorname{IgA}$, and $\operatorname{IgM}$ antibody titres after eradication of Helicobacter pylori. Lancet 1992; 339: $893-895$.

19. Logan RPH, Walker MM, Misiewicz JJ, Gummett PA, Karim $\mathrm{QN}$, Baron JH. Changes in the intragastric distribution of Helicobacter pylori during treatment with omeprazole. Gut 1995; 36: 12-16. 